\title{
14 Discusión
}

De acuerdo con el discurso transmitido por los libros de texto gratuitos, el MCI de MEXICANO está compuesto por ocho modelos cognitivos: el modelo del CIVISMO, de la FAMILIA, de la CULTURA, del TERRITORIO, de la PATRIA, de la HISTORIA NACIONAL, del FENOTIPO y de EL OTRO. Tales modelos aparecen bien definidos en los primeros libros entregados de manera gratuita en 1960; sin embargo, con el paso del tiempo y según la ideología del gobierno que promovió la reforma educativa, estos modelos fueron tomando otra forma o incluso algunos de ellos desaparecieron por completo. El énfasis que los manuales de las diferentes generaciones pusieron en los distintos modelos cognitivos se refleja, en la mayoría de los casos, en el discurso y las narrativas de personas que estudiaron con esos materiales.

Los primeros libros, los libros de "la Patria", como lo advierte el mismo sobrenombre que sus productores les dieron, presentan un discurso altamente nacionalista que correspondía perfectamente con los objetivos que buscaba alcanzar el gobierno de Adolfo López Mateos: lograr la unificación nacional, fomentar el amor por la patria, promover la conciencia de solidaridad y justicia, así como reforzar la identidad mexicana a través de las tradiciones y las costumbres. Las condiciones socio políticas en las que surgieron estos libros fueron de crecimiento industrial y económico. Estuvieron rodeados por el contexto histórico de la Guerra Fría, la cual hizo que México acogiera y replanteara ciertas ideas: la oposición democracia/comunismo y la recuperación de los símbolos originados por la Revolución mexicana. Asimismo, la reciente Revolución cubana obligó al gobierno mexicano a consolidar una específica identidad nacional. La necesidad de unificación ideológica favoreció la aparición de los LTG. Así pues, los manuales representaron la base mínima que sustentaría una educación homogénea, principio que el gobierno mexicano nunca estuvo dispuestos a negociar.

Los modelos cognitivos componentes del MCI de MEXICANo fueron elaborados mediante conceptos particulares y aparecieron con un orden específico. La progresión con que se construyeron a lo largo de las lecturas favoreció la adquisición de la imagen de nación esperada a partir de conocimientos familiares para los niños. Así, por ejemplo, el modelo de la FAMiLIA sirvió de fuente para conceptualizar metafóricamente el concepto de patria. El MCI de PADRE fue la base para la conceptualización de la figura de los héroes nacionales. El modelo cívico, instanciado primeramente en las acciones de los niños de las lecturas, fue relacionado con el comportamiento ideal de los héroes. Las estrategias lingüísticas e icónicas utilizadas reflejan distintas operaciones de conceptualización como metáforas, fusiones conceptuales, metonimias y dinámicas de fuerzas de gran impacto debido al componente emocional que contenían. En efecto, el principal componente

Ә Open Access. (C) 2021 Alba N. García Agüero, published by De Gruyter. (c) BY-NC-ND This work is licensed under the Creative Commons Attribution-NonCommercial-NoDerivatives 4.0 International License.

https://doi.org/10.1515/9783110722383-015 
de la noción de patria - no solo en estos libros- es emotivo: los productores textuales establecen dentro de este modelo cognitivo nociones del marco de la GUERRA: morir, sacrificarse, luchar, sangre, héroes; del marco de la FAMILIA: madre, padre, amor, hogar, protección; de la RELIGIÓN: adorar, mártires, ídolos, santos, sacrificio. El modelo de PATRIA, como componente central del MCI de IDENTIDAD MEXICANA en estos libros, coincide perfectamente con la ideología y objetivos del gobierno de aquella época; sin embargo, será uno de los principales modelos que se modificará en la siguiente generación de LTG. Otro modelo muy llamativo en estos manuales y que será prácticamente borrado en las siguientes generaciones, es el de EL OTRO. En la primera generación tanto el otro como el nosotros aparecen muy bien definidos, lo cual permite el contraste y la diferenciación entre ambos. El mexicano prototípico es definido por sus acciones cívico-patrióticas y por su fenotipo, ostentado en el dibujo de un niño de tez morena clara de vestimenta citadina. El otro es instanciado por el español, el indígena y, en mucho menor medida, el norteamericano (1 oc.). El colectivo español está representado por los conquistadores del s. XVI y especialmente por Hernán Cortés. Este grupo es calificado a partir de nociones como violencia, crueldad, avaricia y maldad. El indígena por su parte también recibe características negativas, pero de otra índole: se le asocia con nociones como ignorancia, incivilización, desamparo, mundo rural, lejanía. El discurso expuesto en los libros con respecto a esta figura promueve ideologemas que focalizan la superioridad del mexicano prototípico. Este mensaje se comunica a través de texto, pero en gran medida a partir de imágenes. De esta manera, aun cuando uno de los objetivos del gobierno era incluir al indígena como parte del colectivo mexicano, el discurso provoca lo contrario al alejarlo visual y verbalmente del prototipo, desagentivizándolo, presentándolo en poquísimas ocasiones (13 oc.) con respecto al niño idealizado (135 occ.) y no relacionándolo con el nosotros.

Como se puede observar en el gráfico 1, los modelos cognitivos que conforman la identidad mexicana en los libros de "La patria" están relacionados estrechamente unos con otros. El gráfico muestra, además, el grado de representación que tiene cada modelo, siendo los más recurrentes la FAMILIA (186 oc.), el FENOTIPO (135 oc.), el CIVISMO (118 oc.) y la PATRIA (71 oc.). Los siguen los modelos de la HISTORIA NACIONAL (52 oc.), la CULTURA ( 27 oc.), el OTRO ( 27 oc.) y, finalmente, el TERRITORIO (18 oc.).

Por lo que se refiere a la parte empírica, encontramos que los modelos cognitivos del MCI de IDENTIDAD MEXICANA propuestos por los primeros libros aparecen también en las narrativas y el discurso de los entrevistados de esta generación. Su aparición era de esperarse debido a que el estímulo que elicitaría las narrativas fue el mismo libro. Lo relevante para esta investigación es que el grado de atención que se pone a ciertos modelos corresponde con el peso que se les da en los 
libros (compárense gráficos 1 y 5). Por ejemplo, esta generación es la que más habla de la familia, lo cual coincide con el nivel de relevancia que le otorgan los primeros manuales. La FAMILIA, además, fue relacionada metafóricamente con la escuela por la mitad de los entrevistados, los cuales evocaron el ideologema promovido por el discurso escolar "la escuela es el segundo hogar". Esto es, fue la única generación que evocó emociones, sobre todo positivas, ligadas a sus maestros: algunos sentían agradecimiento, admiración, cariño y hasta enamoramiento.

Como sus libros, este grupo es el que cita más valores cívicos en sus narrativas y evocó el ideologema “el mexicano es honesto y respeta al prójimo”. Por lo que respecta al modelo de la PATRIA, también como los libros esta generación lo relaciona con el marco de la RELIGIÓN, principalmente cuando refiere la ceremonia cívica de honores a la bandera. Aunque los símbolos nacionales ganan un amplio espacio en las entrevistas (60 oc.), no son la generación que más los refiere. Con excepción de una entrevistada, todos se posicionaron a favor de las ceremonias cívicas y evocaron el ideologema "los mexicanos aman y honran con ceremonias a la patria”. El modelo de la HISTORIA instanciado por los personajes nacionales apareció de manera más amplia (53 oc.) que en otras generaciones, coincidiendo con los libros, los cuales también son los que más ocurrencias presentan (52oc.). Asimismo, fue el grupo que más habla de héroes (10 oc.). La instanciación del pasado prehispánico estuvo presente en las entrevistas (45 oc.). Las narrativas y los discursos argumentativos que emergieron sobre este tema reflejan cierta exaltación hacia tales culturas. Los hechos históricos que aparecieron en las narrativas fueron la Conquista, la Independencia y la Revolución. En suma, a partir de la narración de las acciones de los personajes históricos surgió el ideologema "por sus acciones y sacrificios los héroes nacionales son dignos de admiración, veneración y remembranza colectiva”.

El modelo CULTURAL fue también muy recurrente (48 oc.) debido a que los entrevistados desarrollaron narrativas sobre las celebraciones escolares que realizaban de niños, en las que había música, comida, bailes y trajes mexicanos. El modelo de EL OTRO apareció representado por la figura del conquistador español. $\mathrm{Al}$ igual que los libros, los entrevistados conceptualizaron esta figura con los mismos atributos expuestos por los libros (violencia, crueldad, avaricia y maldad) e incluso hicieron uso de metáforas y metonimias muy potentes emotivamente para enfatizar dichos atributos. Así pues, en las narrativas de esta generación se reflejan claramente los ideologemas "los españoles fueron los enemigos que atacaron a mi grupo" y "los españoles eran codiciosos y crueles”. La instanciación del indígena como el otro separado del nosotros se refleja en el ideologema "no somos ni indígenas ni españoles, sino mestizos" aparecido en el discurso de dos entrevistados. 
El modelo del TERRITORIO solo fue evocado por tres particiantes al mencionar palabras que representan la mexicanidad, pero no en las narrativas. Finalmente, el modelo del FENOTIPO, presente en casi cada página de los libros, no emergió en las entrevistas.

Una peculiaridad de este grupo de entrevistados es que, a pesar de que todos se posicionaron a favor de sus libros expresando un gran gusto y melancolía al verlos, explícita o indirectamente todos se posicionaron en contra del sistema educativo de su época, al cual referían como muy básico, conservador; lo criticaron también por su método memorístico, por fomentar tabús y por no propiciar el razonamiento. Asimismo, todos pusieron en duda la verdad histórica presentada en los libros y referida por sus maestros. No obstante, la visión crítica que mostraron en un nivel 2 de posicionamiento - con la cual se distanciaron del discurso educativo (nivel 3) -, se difuminó ante el estímulo visual de la portada del libro para dar paso a la emotividad y a la aceptación de los manuales.

La segunda generación de LTG, "los libros de los juguetes" surgen en el marco de una política educativa creada en respuesta al movimiento estudiantil reprimido brutalmente por el gobierno de Gustavo Díaz Ordaz en 1968. Son editados tras la reforma promovida por su sucesor, Luis Echeverría Álvarez, durante su sexenio (1970-1976). Su gobierno se distinguió por revitalizar el populismo, mostrar una aparente imagen de izquierda y por una visión tercermundista que se refleja en los libros de texto. En efecto, los nuevos manuales tenían como objetivo general reajustar la visión ideológica y neutralizar la agitación de la población y de grupos de intelectuales. En particular, buscaban fomentar una actitud científica y crítica de los escolares en consonancia con los valores de la "apertura democrática”, y explicar los acontecimientos históricos más a partir de las fuerzas sociales y menos en función de la intervención de los héroes nacionales. Así pues, la visión nacionalista y heroica de los primeros libros que giraban alrededor del mexicano, la familia y la patria es abandonada para adoptar una orientación tercermundista que ubicaba al niño en un contexto mundial.

Estos libros no estuvieron exentos de ataques y críticas. A diferencia de las inconformidades que causaron los libros anteriores debido a su obligatoriedad, esta vez los ataques estuvieron dirigidos a los contenidos, los cuales fueron acusados por la derecha mexicana de ser comunistas, marxistas y antinacionalistas.

Visualmente, estos manuales presentaron un cambio radical: las páginas se cubrieron de fotografías y en lugar de dos volúmenes se crean cuatro, uno para cada materia, además de un libro recortable. Los modelos cognitivos también se modificaron. El modelo de la PATRIA perdió el marco religioso y las nociones de devoción, entrega y sacrificio de la generación anterior. Además, ya no es relacionado con el marco de la FAMILIA (hasta la reimpresión de 1975). La misma palabra patria desapareció de los manuales y fue sustituida por México. Este 
nuevo modelo fue entendido en términos de territorio, es decir, se perfilan las nociones de geografia, demografia, topografía y urbanismo (esta última relacionada con la modernidad). Como se puede observar en el gráfico 2, el modelo de la PATRIA tiene muy poca representación en los libros (31 oc.) El modelo del CIVISMO desapareció casi por completo (20 oc.). Sus instanciaciones son cinco: la colaboración en la escuela (3 oc.) y en la familia (2 oc.); la limpieza (2 oc.); la higiene personal (11 oc.), y el respeto (1 oc.). Sin embargo, ninguna de estas elaboraciones se atribuye explícitamente al mexicano ideal, sino a cualquier ciudadano del mundo. El modelo FAMILIAR (60 oc.) compite con el de la CULTURA (57 oc.), lo cual es esperable debido a que los productores textuales tomaron en consideración el aspecto infantil para la creación de los libros. La familia, pues, es un elemento que se encuentra indudablemente dentro del marco cognitivo de la infancia, así como los juguetes mexicanos considerados artesanías y ubicados dentro el modelo de la CULTURA. La HISTORIA es el siguiente modelo en orden de ocurrencias (41 oc.). En lo que concierne al modelo del OTRO, también fue difuminado: la figura del español desapareció por completo y el indígena no fue nominado ni descrito verbalmente. Se ven algunas fotos en las que aparece esta figura, pero las tomas crean gran distancia social y ningún involucramiento con el lector. En esta generación el otro fue representado por distintas lenguas (dos europeas y dos indígenas mexicanas) o por imágenes de niños de otras nacionalidades. Los países que sirvieron como ejemplo pertenecen al tercer mundo, lo cual demuestra una correspondencia con la ideología gubernamental. La colocación de las lenguas y las imágenes en el espacio visual privilegia ciertas etnias (las europeas de características arias) y lenguas (el inglés y el francés). El modelo del FENOTIPO se mantuvo, con la diferencia de que la representación, al ser realista (por tratarse de fotografías), define con más exactitud las características del mexicano prototípico. El fenotipo más saliente, recurrente y aceptado es el de niños de tez morena clara, pelo y ojos oscuros, vestidos de manera citadina. La gran prominencia de este modelo (685 oc.) se debe al aumento del número de manuales y a la cantidad de fotos que estos presentan (aunque también fueron computados los dibujos que poseían las características del prototipo). Sin embargo, como apuntamos más arriba, este dato nos permite sostener, por un lado, que la escasa aparición del indígena con respecto al fenotipo ideal representa un mecanismo de discriminación que borra esta figura del MCI identitario. Por otro lado, la exorbitante aparición de un fenotipo específico indica que es este el prototipo idealizado que los manuales proponen.

Como lo muestra el gráfico 2, los modelos cognitivos que presenta esta generación de libros están mucho menos cohesionados que los propuestos por los libros de "La patria”. 
Las entrevistas a personas que estudiaron con los materiales de los setenta demuestran que la relación emotiva que la generación anterior mostró hacia los maestros se ha difuminado bastante, ya que los entrevistados no refirieron nombres y solo la entrevistada de edad más cercana a la generación anterior evocó el ideologema "la escuela es el segundo hogar". El modelo de la PATRIA, a diferencia de lo que proponen los libros, apareció de manera muy vívida. Es decir, se observa un nacionalismo demostrado por la emoción que los entrevistados comunicaron hacia las ceremonias cívicas, el cual no corresponde con la ideología de los manuales, que, como mencionamos anteriormente, fueron acusados incluso de ser antinacionalistas. Lo anterior sugiere que las representaciones mentales no son un calco exacto de los libros. Sin embargo, el hecho de que los cinco entrevistados hayan referido puntos de vista coincidentes hacia estas prácticas nos hace suponer que, en la práctica educativa, estas actividades seguían teniendo un alto valor. Cabe mencionar también que hemos encontrado que los entrevistados mayores, es decir, los más cercanos a la generación anterior, ostentan un discurso más emotivo con respecto a los temas cívicos (Sofía, Joel), mientras que los más alejados (Nora, Raúl) se posicionan cada vez más distantes del discurso patriótico. En el gráfico 5 se puede observar que la referencia de estos entrevistados a los símbolos patrios (69 oc.) es mayor que la de la primera generación. La importancia que estos dieron a la escolta y a la descripción de la ceremonia de honores a la bandera arrojó este resultado. Así pues, los ideologemas que emergieron en las narrativas fueron: "La bandera es México" y "Sentimos cariño por el país y por lo tanto por la bandera también”.

En cuanto al modelo de la HISTORIA, esta generación es la que hizo el mayor énfasis en las culturas prehispánicas (65 oc.). Todos los entrevistados demostraron gran orgullo y admiración por ellas y evocaron el ideologema "nuestros antepasados pertenecían a las culturas prehispánicas”. El enaltecimiento y recurrente alusión al mundo prehispánico no coincide con el tratamiento que se le da en los libros de primer grado. Sin embargo, tanto esta como la siguiente generación compartieron exactamente los mismos libros de Ciencias Sociales de 3 으 a 6 으 en los que se da a los pueblos mesoamericanos -en especial a los aztecas - un papel mítico y decorativo para sostener el discurso dominante del mestizaje, según demuestra el estudio de Álvarez de Testa (1992). Podemos deducir, pues, que este podría ser uno de los motivos que influyeron para que estas generaciones (segunda y tercera) perfilen con tanta precisión, admiración e insistencia la historia prehispánica perteneciente al modelo de la HISTORIA NACIONAL. Otra discordancia que encontramos entre el discurso de los libros y el de los entrevistados radica en la perspectiva ideológica con la que los manuales trataban a los personajes históricos. Mientras que los libros restan heroísmo patriótico al comportamiento de estos personajes focalizando al pueblo mexicano como el promo- 
tor de los cambios históricos, ninguno de los participantes ostentó esta idea. Así, tomando únicamente en cuenta nuestros datos, se podría decir que uno de los principales objetivos ideológicos planteados por la reforma educativa de los setenta no fue plenamente alcanzado.

El peso que los entrevistados dieron los modelos de la CULTURA (45 oc.), la FAMILIA (39 oc.) y el CIVISMO coincide con la prominencia que les otorgan los libros (ver Gráfico 5). En cuanto al modelo de EL OTRO, instanciado por la figura de los conquistadores españoles, apareció bien representada en las narrativas, aun cuando no hay rastro de ella en los libros de primero de primaria. El español sigue siendo conceptualizado como el enemigo que con actos atroces despojó al nosotros del territorio y las costumbres. En las narrativas sobre la Conquista se observa una fuerte identificación con el pueblo azteca, mientras que se marca una postura de distancia con respecto del español, al cual dos participantes le atribuyen otras cualidades: la riqueza y la tez blanca. En efecto, el color de piel es una de las principales características distintivas del mexicano según esta generación, la cual evoca el ideologema "hay características más agradables y mejor aceptadas: piel más blanca, vestimenta citadina”. Por lo tanto, nuestro grupo de entrevistados mostró alinearse con el fenotipo que los libros establecieron.

La tercera generación de LTG no se editó a raíz de una nueva reforma educa-

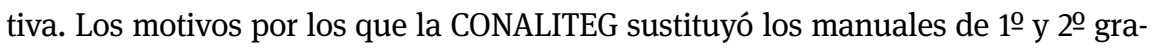
dos en 1980 fueron de cariz pedagógico. En efecto, se decidió volver a integrar las materias - como en la primera generación - a fin de ajustar la enseñanza a la propuesta pedagógica basada en el principio del pensamiento sincrético del niño. Así, se editaron solo dos manuales con sus correspondientes volúmenes recortables, que difirieron notablemente de "los libros de los juguetes".

Los libros de la tercera generación circularon en un periodo de grave crisis financiera iniciada en 1981. Miguel de la Madrid recibió el poder (1982) en medio de esa crisis que estuvo a punto de afectar incluso a la producción de los LTG, ya que se redujo considerablemente el presupuesto a la CONALITEG al grado de considerar entregar los libros en calidad de préstamo. Ideológicamente, este gobierno le dio la espalda a la visión populista del régimen echeverrista y, a raíz de la crisis económica, atribuyó al populismo la deficiencia principal de la política mexicana. El ataque a la corriente ideológica sirvió al gobierno para reprimir e ignorar demandas populares. De esta manera, inicia la transformación del modelo de nación de populista a neoliberal.

Los libros integrados de los ochenta vuelven a tomar el matiz patriótico atenuado en la generación anterior. Aunque se mantiene la conceptualización de MÉxICo como territorio, se concede mucho más espacio a sus elaboraciones (85 oc. vs. 31 en los setenta) y, dentro de este modelo, se recogen elementos 
del marco de la PATRIA. Es decir, que se incrementa la aparición de símbolos nacionales y se vuelve a mostrar el comportamiento cívico-patriótico perfilando los sentimientos de cariño y respeto. Lo anterior se muestra a través de la representación realista de fotos de niños y niñas que rinden honor a tales insignias. El modelo FAMILIAR también adquiere un espacio mayor que en los libros anteriores (111 oc. vs. 60 oc. de los setenta), pero no es relacionado metafóricamente con la patria como en la primera generación. El modelo de la FAMILIA, que era uno de los componentes principales del MCI de IDENTIDAD MEXICANA en 1960, pierde relevancia constitutiva en las siguientes dos décadas; sin embargo, ha sido interesante observar la evolución del modelo: en los primeros libros la familia mexicana ideal estaba constituida por el padre, la madre y dos hijos (niño y niña), cada uno de los cuales cumplía con los roles prototípicos: la madre amorosa, ama de casa, encargada de los hijos y supeditada al padre. El padre era conceptualizado como el proveedor, protector y cariñoso, que trabaja fuera de casa y es la cabeza del hogar. En los setenta las figuras se mantienen casi intactas, pero se le da menos prominencia al padre y por primera y única vez se relaciona a la madre con la educación intelectual de los hijos (1 oc.). En los ochenta el rol de las figuras se nivela bastante: se observan fotografías donde ambos realizan tareas que tienen que ver con el cuidado de los hijos; sin embargo, la madre sigue siendo relacionada con el marco de la COMIDA y las TAREAS DOMÉSTICAS y el padre aparece como la figura más prominente y es relacionado con la responsabilidad económica.

El modelo de la CULTURA (51 oc.) es, después del de la FAMILIA, uno de los más sobresalientes en estos libros. El modelo está sostenido por ideologemas que focalizan la alegría de las tradiciones y el apetitoso sabor de la comida. Pero también son generalizantes, por ejemplo, advierten que todos los mexicanos comen tacos y chile. Dentro de este modelo generalizante se encuentra el castellano como la lengua de los mexicanos. En cuanto al modelo de la HISTORIA NACIONAL (41 oc.) es desarrollado un poco más que en los libros de los setenta ( 35 oc.) pero menos que en los de los sesenta (52 oc.). Las elaboraciones de este modelo son, como en los libros anteriores, la historia prehispánica y los personajes históricos, pero se agrega la prehistoria y se hace más énfasis en el presente y futuro de México. La representación que tienen las culturas mesoamericanas en ambas generaciones es casi idéntica (14. oc. en 1972 y 15 oc. en 1980), lo mismo que el peso que les dan a los personajes históricos (21 oc. y 18), pero la referencia a la modernidad del presente de México es más marcada en la tercera generación ( 2 oc. vs. 4 oc.). Como lo muestra el gráfico 3, el modelo del CIVISMo es uno de los menos representados. Aumenta el número de ocurrencias (33 oc.) con respecto de los libros anteriores, pero reduce las instanciaciones a tres (limpieza 3 oc.; aseo personal 16 oc. y colaboración 14 oc.). Al igual que sus antecesores, estos libros tampoco atribuyen explícitamente 
estos comportamientos al mexicano. Finalmente, como elaboraciones del modelo de EL OTRO, vuelve a aparecer la figura del español (5 oc.). Aunque sin usar calificativos para este grupo, los ideologemas "nuestro pasado prehispánico era majestuoso" y "los españoles acabaron con su majestuosidad" hacen que se conceptualice como el outgroup enemigo que provocó un cambio negativo para el ingroup. Por lo que se refiere al indígena, es conceptualizado como una figura folklórica, que proviene de un lugar lejano y con la cual el nosotros no se puede comunicar. En este sentido, la lengua es considerada como un aspecto distintivo entre el grupo indígena y el nosotros mexicano.

Por lo que respecta a los hallazgos a partir de las narrativas de los entrevistados, hemos observado un cambio entre esta y las generaciones anteriores en cuanto al discurso patriótico presentado por los libros y el sistema educativo: mientras que en las primeras dos hay bastante homogeneidad, en la generación de los ochenta hay heterogeneidad y contradicciones en las posturas: dos entrevistados se alinean con el discurso de amor a la patria y el respeto a los símbolos, por lo que evocan varias veces los ideologemas "respetamos la bandera y nos sentimos orgullosos de ella, por eso le hacemos ceremonias" y "sentimos cariño por México”. Otro de los participantes se alinea con este discurso, pero en ocasiones refiere cierta incredulidad; otro más se muestra neutral y poco emotivo y la única participante se distancia totalmente. Por lo que respecta a las prácticas educativas se observan incongruencias de posicionamiento, pues por un lado las critican, pero al mismo tiempo las justifican. De igual manera sucede con los libros: los participantes oscilan entre la aceptación y el rechazo de estos. El regreso al patriotismo (más mesurado que en 1960) que reflejan los manuales es observable en la mitad de los participantes. Este matiz se puede corroborar en el gráfico 5, donde se muestra que esta generación es la que más usa las palabras patria y México y que hace referencia a símbolos nacionales (73 oc.). Lo anterior se debe a que narran más historias sobre la escolta y las ceremonias cívicas que otras generaciones.

El modelo de la HISTORIA es representado por el periodo prehispánico, la Conquista, la Colonia, la Independencia, la Revolución y la Reforma, así como por sus personajes. Estos últimos son llamados principalmente así: "personajes históricos", y no "héroes" como se aprecia en el gráfico 5. Además, la idealización de estos es casi nula. El mundo prehispánico está también presente (46 oc.) pero, aunque los entrevistados siguen expresando admiración por estas culturas, a diferencia de los participantes de la generación anterior, no se incluyen dentro del colectivo prehispánico. Es decir, la admiración que sienten la transmiten desde un punto de vista objetivo, en el sentido de que se colocan fuera de la escena. En suma, el ideologema que evocaron todos los entrevistados fue "los aztecas (y otras culturas mesoamericanas como la maya) eran asombrosos, ingeniosos y cultos”. 
El modelo CULTURAL también es más citado (46 oc.) por los participantes de esta generación que por los de la precedente. Este modelo se refleja a través de narrativas que tocan el tema de las expresiones artísticas (danza y música), tradiciones como el Día de Muertos y la comida mexicana. El ideologema recurrente en las entrevistas es "los mexicanos poseemos tradiciones que celebramos de manera muy alegre y somos felices de participar en ellas”. En cuanto al modelo del CIVISMO, este adquiere prominencia debido a la repetición de la palabra respeto, pero no como uno de los valores de la comunidad mexicana, sino de las culturas prehispánicas, orientales o europeas, o bien al practicado por obligación hacia los maestros; o, simplemente, por la mención de la famosa frase de Juárez que tuvieron que recitar. El único valor cívico atribuido al colectivo mexicano fue el de fraternidad.

El modelo del OTRO estuvo representado por la figura del español, la cual aparece, pero de manera mucho más neutral que en las pasadas generaciones. $\mathrm{O}$ sea, se conceptualiza con menos emotividad y pierde aún más la connotación de enemigo cruel. La segunda figura que instancia este modelo es el indígena, el cual aparece en una de las narrativas experienciales de un entrevistado y es relacionado directamente con la lengua. A partir del comportamiento discriminatorio de los personajes en la narrativa se evoca el ideologema promovido por los libros "hay otros que no son como nosotros, son extraños, viven lejos y no nos podemos comunicar con ellos". Finalmente, el modelo del FENOTIPO apareció a partir del estímulo visual de la portada de los primeros libros. Todos los participantes reconocieron las características de la mujer como prototípicas de la comunidad mexicana. El color moreno de piel fue una de las particularidades que todos los participantes focalizaron en esta figura. No obstante, solo uno de ellos se identificó con este fenotipo. Mediante diferentes estrategias lingüísticas, el resto se distanció de la representación, no incluyéndose dentro del grupo en el que categorizaron a esta figura. A diferencia de los libros que presentan un fenotipo de mexicano más bien uniforme, dos entrevistados refirieron la diversidad física que existe en México; sin embargo, no se identificaron como miembros de estos colectivos e incluso uno de los participantes aludió a un grupo dominante al que él pertenece.

Los LTG de la cuarta generación se editaron tras una reforma educativa (1993) promovida durante el sexenio presidencial de Carlos Salinas de Gortari (1988-1994), quien instauró una economía y una cultura globalizadas y un proyecto de "modernización” neoliberal. Bajo la nueva ideología, los libros de esta generación buscaban resguardar valores y tradiciones de la nacionalidad mexicana y preparar a los estudiantes para que pudieran competir con las naciones de vanguardia. Esta generación comenzó a circular en 1994, después de que en 
1992 "los libros de la prueba operatoria” crearan gran polémica cuando se descubrió que la editorial encargada de realizarlos recibió una alta suma de dinero para difundir en los manuales propaganda del gobierno salinista. Por tal motivo, tuvieron que ser desechados un año después. La repartición de los nuevos libros tuvo lugar el mismo año del levantamiento armado del Ejército Zapatista de Liberación Nacional y con la entrada en vigor del TLC, a partir del cual los indígenas de Chiapas perderían derechos sobre sus tierras. El alzamiento demandaba justicia y reivindicación de los derechos de los pueblos indios de México. Este fue uno de los problemas políticos y sociales que los libros de esta generación ignoraron.

Los libros se volvieron a separar por asignaturas y los niños de primer grado recibieron en 1994 un paquete de siete manuales, incluido un libro integrado. El libro de Español y de Lecturas contenían la gran mayoría de textos de los manuales de los ochenta. En 1997 fue sustituido el libro de Lecturas por otro que lleva el mismo nombre, cuyos contenidos fueron completamente distintos. Esta generación se conservó hasta la renovación de los LTG en 2008.

A nivel visual, estos libros vuelven a los dibujos como en 1960, pero esta vez se opta por una tendencia no realista promovida por la saturación de color y la caricatura, recursos que no definen ningún fenotipo y da a las figuras un toque incluso humorístico. Pero, además, los manuales reflejan un aspecto infantil y lúdico, en especial los libros de Español y de Lecturas, ya que incorporan cuentos cuyos personajes son duendes, brujas, hadas y animales antropomorfizados. Debido a que evocan permanentemente el marco INFANTIL, esta generación es la que presenta más ocurrencias de vocablos e imágenes correspondientes al modelo de la FAMILIA (234 oc.). Los miembros de este modelo siguen manteniendo el MCI conservador compuesto por el padre, la madre, los hijos, pero se da mucho más peso a otros miembros como los abuelos y aparece incluso el perro. A pesar de la distancia de 17 años que separan la creación de las últimas dos generaciones, la figura más prominente, la madre, se vuelve a presentar únicamente como ama de casa. El modelo del TERRITORIO (oc. 82) es el más representado después del de la FAMILIA. En esta generación es menos extensa la concepción de las riquezas naturales, ya que, por ejemplo, no hay aglutinaciones tan amplias de palabras referentes a este marco como en otras generaciones. La diversidad es considerada como parte del MCI de MÉxiCo. Se concibe la diversidad como algo positivo cuando se habla de opiniones, pero cuando se habla de personas la palabra diferencias perfila la otredad, propiedad que será adjudicada al indígena. El modelo de la CULTURA también ocupa buena parte de los libros (63 oc.). Se enfatiza el folklor mexicano, es decir, las expresiones artísticas populares, y también se presentan festejos tradicionales como el Día de Muertos. Las celebraciones cívicas se conceptualizan dentro del mismo marco de las TRADICIONES perfilando también 
el aspecto festivo. En relación con este marco los libros promueven ideologemas que aluden a la alegría y colorido de los festejos tradicionales y hacen también la generalización sobre las costumbres culinarias de los mexicanos. El marco de la HISTORIA NACIONAL (41 oc.) tiene casi el mismo peso que le dieron las dos generaciones anteriores. Es evocado mediante efemérides que son colocadas en el orden en que acontecieron y son presentadas por medio de collages que brindan a las lecturas un tono relajado que muchas veces activa el marco INFANTIL, perfilando el marco del JUEGo. Los ideologemas que promueven estos libros con respecto a este modelo apuntan a la obligación de festejar y recordar ciertos acontecimientos históricos.

Los comportamientos y valores esperados del mexicano ideal no se plasman en los libros de primero. Se publica un manual para los últimos tres años de la primaria donde se toca este tema. En los libros objeto de nuestro análisis, el modelo del CIVISMo (27 oc.) está representado por comportamientos de carácter universal como la colaboración o la ayuda y, por primera vez, la protección del medio ambiente y la tolerancia (aunque este último de manera implícita). Las figuras que representan el modelo de EL OTRO son el ejército de Estados Unidos, los franceses y los españoles. A pesar de que son tratados como el enemigo a partir de la operación conceptual de dinámica de fuerzas, la distancia temporal que se enfatiza al inicio de cada texto atenúa la amenaza. En esta generación el indígena desaparece casi al cien por ciento. Solamente se presenta en una fotografía en blanco y negro y es evocado en una lectura que habla de las lenguas indígenas como preludio del tema sobre la diversidad. Aunque se percibe un intento de integrarlo dentro de la comunidad mexicana, la palabra distinto que perfila la noción de otredad se asocia al indígena, con lo cual vuelve a quedar lejos del centro de la categoría nosotros.

Por lo que respecta a los hallazgos recabados de las entrevistas, hemos encontrado mucha más homogeneidad que en la generación anterior en cuanto a la postura que adoptaron frente al discurso oficial y las prácticas educativas. Esta es la generación que más se apartó de tal discurso, en especial del patriótico que aún presentan los libros. Por ejemplo, todos los entrevistados expresaron de diferentes maneras su desapego emotivo a las ceremonias cívicas. Evaluaron explícitamente estas prácticas como aburridas o refirieron el sentido de obligación y absurdo que representaban para ellos. En sus narrativas se refleja una crítica directa hacia algunos ideologemas promovidos por los libros y el sistema educativo sobre el amor y respeto a la bandera, las ceremonias cívicas y hacia la patria. Y en un caso, una entrevistada expresó su distanciamiento consciente del ideologema "los símbolos nacionales representan lo que más queremos", postura que, sin embargo, le produjo un sentido de culpa. En el gráfico 5 se puede observar 
que esta es la generación que menos menciona las palabras México (40 oc.), patria (9 oc.) y país (10 oc.) y hace menos alusión a los símbolos nacionales (53oc.).

En cuanto al modelo de la HISTORIA, se observa una crítica dirigida al discurso oficial como en la generación de los sesenta, pero a diferencia de esta, no refirieron explícitamente que el sistema educativo miente, sino más bien afirmaron que no cuenta la historia completa, o bien repitieron el discurso histórico escolar usando distintos recursos prosódicos y estilísticos (ironía, sarcasmo) para ridiculizarlo. Además, refirieron que la narración de la historia que les transmitían en la escuela tenía un sentido lúdico. Esto es, las representaciones teatrales con las que les inculcaban estos conocimientos eran divertidas porque eran como un juego. En suma, los entrevistados se divirtieron ridiculizando la historia, lo cual corresponde en cierta medida con el aspecto lúdico que transmiten los collages con los que se presenta el conocimiento histórico en los libros. En cuanto a las culturas prehispánicas, tópico predilecto de las antiguas generaciones para referir el origen sobre el que se basa la identidad mexicana, esta generación hace muy poca alusión a él. Lo anterior se puede constatar en el gráfico 5 (17 oc.) y en las respuestas a la petición de palabras e imágenes (4 oc.) que representan la mexicanidad.

Aunque la cuarta generación de libros es la que presenta más elaboraciones y ocurrencias (63) del modelo CULTURAL, los entrevistados de este grupo fueron los que menos hablaron de tradiciones mexicanas o adoptaron una posición de distanciamiento con una de las pocas que surgió (el Día de Muertos). Si tomamos en cuenta que esta generación vivió su infancia durante la revolución informática y la apertura a la globalización, es comprensible que en las escuelas no se practicaran, como en el caso de las generaciones anteriores, con tanta pureza las tradiciones mexicanas. Como lo refieren algunos de los entrevistados, en esa época ya se observaba el sincretismo con otras tradiciones como el Halloween o la Navidad, prácticas que no habían sido nominadas anteriormente. Así las cosas, al no haber celebrado en la escuela muchas tradiciones mexicanas, los entrevistados no las pudieron referir en sus narrativas. La comida, sin embargo, es una instanciación del modelo CULTURAL que sigue siendo muy aceptado como parte de la identidad nacional.

Los valores cívicos desaparecieron casi por completo en esta generación (5oc.), lo cual corresponde con el poco peso que les dan los libros. Lo mismo sucede con la figura del español como instanciación del modelo de EL OTRO: las pocas veces que surgió en el discurso de los entrevistados (3 oc.), apareció sin calificativos ni juicios de valor. La figura del indígena estuvo un poco más representada (8 oc.) y fue relacionada con la lengua. Se evocó el ideologema "hay otros mexicanos que hablan lenguas indígenas pero la mayoría de los mexicanos hablamos español"; sin embargo, en ningún caso se advierte una identificación completa con este 
grupo. Por último, el modelo del FENOTIPO, una vez más, apareció en los discursos y narrativas que emergieron del estímulo visual de la pintura "La patria". Todos los entrevistados reconocieron en la mujer de la portada el fenotipo mexicano y focalizaron el color de piel como hicieron las generaciones anteriores. Evocaron, pues, el ideologema "el color de piel nos hace ser diferentes unos de otros". Así pues, a pesar de que afirmaron que las características de la figura correspondían a las del mexicano, ninguno se identificó con ella.

Para concluir, podemos decir que la supuesta intención que proclamaba la reforma educativa de resguardar valores de la nacionalidad mexicana no se refleja en las entrevistas, pero tampoco es bastante clara en los libros. Esto es, mientras que solo el Libro Integrado recoge estos temas de manera lúdica y poco profunda, el resto de los manuales presentan lecturas y actividades que remiten al marco INFANTIL y apuntan hacia la internacionalización. Asimismo, de acuerdo con los participantes, el sistema escolar de la época abrió sus puertas a otras costumbres en detrimento de las nacionales. Este factor, aunado al bombardeo de información televisiva y de fuentes como el internet, ha influido para que el MCI de IDENTIDAD MEXICANA, propuesto en los manuales, no concuerde del todo con el discurso de los entrevistados.

Fue así como cada una de las generaciones de LTG plantearon un modelo de mexicanidad acorde a la ideología e intereses de los gobiernos en que se produjeron. Las coincidencias entre los libros y las narrativas dejan ver que el discurso oficial fue adquirido, en mayor medida, por los entrevistados de la primera generación y tuvo menos impacto en la última. Así pues, podemos decir que, si bien los mexicanos han recibido por distintos medios el discurso que configura la identidad nacional, los LTG han tenido un papel muy importante para formar y transmitir esta representación colectiva. 